ISSN 1112-9867

\title{
RELIABILITY AND VALIDITY FOR MEASUREMENT OF BODY COMPOSITION: A FIELD METHOD
}

\author{
A. Hashim ${ }^{1 *}$, G. Elumalai ${ }^{1}$, and Z. Ab Rahman ${ }^{1,2}$ \\ ${ }^{1}$ Faculty of Sports Science and Coaching, Universiti Pendidikan Sultan Idris, Tg Malim, \\ Perak, Malaysia \\ ${ }^{2}$ Institut Pendidikan Guru, Kampus Sultan Mizan, Besut, Terengganu
}

Published online: 10 November 2017

\begin{abstract}
Measurement of body composition via a field method has the most popular instruments which are used to estimate the percentage of body fat. Among the instruments used are the Body Mass Index, Bio Impedance Analysis and Skinfold Test. All three of these instruments do not involve high costs, do not require high technical skills, mobile, save time, and are suitable for use in large populations. Because all three instruments can estimate the percentage of body fat, but it is important to identify the most appropriate instruments and have high reliability. Hence, this study was conducted to determine the reliability and convergent validity of the instruments. A total of 40 students, males and females aged between 13 and 14 years participated in this study. The study found that the test retest and Pearson correlation coefficient of reliability for the three instruments is very high, $r=.99$. While the inter class reliability also are at high level with $r=.99$ for Body Mass Index and Bio Impedance Analysis, $r=.96$ for Skinfold test. Intra class reliability coefficient for these three instruments is too high for Body Mass Index $r=.99$, Bio Impedance Analysis $r=.97$, and Skinfold Test $r=.90$.
\end{abstract}

Author Correspondence, e-mail: ahmad@fsskj.upsi.edu.my

doi: http://dx.doi.org/10.4314/jfas.v9i6s.88 
However, Standard Error of Measurement value for all three instruments indicates the Body Mass Index is the most appropriate instrument with a mean value of .000672 compared with other instruments. The findings show that the Body Mass Index is an instrument which is the most accurate and reliable in estimating body fat percentage for the population studied.

Keywords: Reliability, Validity, Body Mass Index, Bio Impedance Analysis and Skinfold Test.

\section{INTRODUCTION}

Previous researchers from local and abroad [14], have proven that obesity is closely related to other chronic diseases such as hypertension, type 2 diabetes, cardiovascular complications, metabolic syndrome and psychological problems for all age levels, gender and races. [29], believes that obesity is a global scale epidemic of the $21^{\text {st }}$ Century due to the increase in the number of cases in both developing and developed nations. Almost all countries in the world face obesity issues because of several factors such as changes in diet intake, lifestyle, physical activity, the surroundings and social-economic level. In Malaysia, the rate of obesity reported among school-going students were 6.03 for males and 4.68 percent for females. Such numbers indicated that there was an increase of 12 percent for males and 13 percent for females [22]. Even though these figures were relatively lower compared to foreign countries such as Jepun which had its level of obesity between 6.1 percent for males and 10.2 percent for females [16], one cannot take such issue lightly without doing anything significant to overcome it. Obesity morbidity often occurs among adults but early symptoms had surfaced from childhood and teenage years. Most obesity-related-cardiovascular diseases among adults were results of childhood obesity [10]. In addition, according to [21], obese teens usually have higher risk at getting health problems when they are adults. Hence, obesity among school children must be given attention so that they can grow up without having to face chronic illness.

Due to the significance of obesity-related issues among school children, Ministry of Education Malaysia has introduced National Physical Fitness Test Standards by including Body Mass Index to determine the level of obesity among Malaysian school students. Obesity, which is known to be associated with excess body fat, has attracted researchers who 
conduct studies that are related to body composition. According to [20], human body composition measurement involves an estimation of body fat percentage: this is to determine the density of an individual's body.

Instruments for the measurement of body composition are divided into two categories namely laboratory and field method. Field method consists which of Body Mass, Skinfold Test and Bio Impedance Analysis often becomes the choice among researchers due to its affordability and mobile equipment. It also does not require high technical skill, saves time and suitable to be conducted on a big population of subjects. Comparatively, laboratory method requires sophisticated and difficult-to-find equipment as well as costly and it demands high technical skills.

Since field method is the common choice among researchers, issues pertaining data reliability and validity can be questioned. Such issues arise because all instruments in field method are not categorized as 'Gold Standard' as compared to Hidrostatic Weighing which is part of a laboratory method which is recognized as one, for the measurement of body composition. Therefore, it is imperative for a research to be carried out to prove the validity, reliability and internal consistency in body composition measurement. One method that is used is by making a comparison between body composition instruments in field method and those from the laboratory methods which are recognized as 'Gold Standard' such as dual-energy x-ray absorptiometry (DXA) and hidrostatic weighing: they are also considered as criteria reference. Nevertheless, the use of 'Gold Standard' instrument is costly and it requires equipment which is difficult to get. On top of that, the 'Gold Standard' instrument requires highly skilled examiners and the assessment is challenging when it involves large group of population. Based on these limitations, convergent validity method ought to be applied and carried out in order to determine an instrument for body composition measurement via field method to be used as criteria in obtaining valid data on body fat in the context of the population studied.

Convergent validity refers to the consensus among various different instruments to measure similar construct [12]. In the context of this study, several body composition measurement in field method such as Body Mass Index, Bio Impedance Analysis, and Skinfold Test were used to measure the percentage of body fat. Convergent validity method is used by previous 
researchers [19]. Even though these instruments were recognized in terms of validity and reliability based on previous studies, not all of them are suitable to be used for a population that is being studied. According to [19], scores from a test can be trusted in a certain condition, managed in a certain way and with certain characteristics of the subject. This is in line with a statement by [2] and [15], which stated that any valid test to be used on 13-year old students is invalid to be to be used for 17 year old students. Clearly, the validity and reliability of an instrument that is proven to be valid and reliable for one population is not necessarily the same for another population. In fact, these instruments depend on the characteristics of the population such as age, gender, ethnic, culture, environment and others.

\subsection{Objectives of the Study}

The main objective of this study is to determine the reliability and convergent validity among three body composition measurement instrument through field method to measure an estimate of body fat percentage of male and female students, bodies aged between 13 and 14 years old in Klang, Selangor.

\section{Research Methodology}

This research aims to determine one out of three body composition measurement that is most accurate through the convergent validity method. Research methodology for this study encompasses methods in data collection, sampling, data analysis and research instrument. It is also used as guidance by the researcher in the process of collecting and analyzing data so that the findings is accurate and can be accepted by all relevant parties as guidelines. Focus is given to several procedures that are conducted in this study such as research design, population and sample, validity and reliability of research instrument, study equipment, data collection procedure and analyses.

\subsection{Participants}

A total of 40 samples were used in this research and they were made of 20 male and female students aged 13 and 14 years old from Sekolah Menengah Kebangsaan Kampung Jawa, Klang and Sekolah Menengah Kebangsaan Pulau Indah, Klang. A pilot study to conduct the 
convergent validity study of measurement instrument in field method. Measurement procedures which were used in this study had received the approval from the school authorities.

\subsection{Instruments and Research Procedure}

Research sample is divided into two different groups based on their genders. Each test station was provided for each group in different rooms. Measuring process was done intermittently between researcher and male research assistant, female expert and female research assistant. However, both happened at the same time for both male and female groups. The researcher and a female expert were assisted by four assistant assessors represented by two male and two female students from the Faculty of Sports Science, Universiti Pendidikan Sultan Idris, Tanjong Malim, Perak. Male samples were assessed by the researcher and male assistant assessors while the female samples were assessed by the female expert and her female assistants. All assistants have attended training to ensure that assessors' objectivity was high among them. According to [3], training between 50 and 100 sessions on the different subjects was needed to obtain reliability technique and measurement method using the caliper. Thus, all assessors had gone for body fat measurement training for 80 times in order to ensure high reliability when they handle measurement procedures. In addition, all assessors were equipped with written and illustrated assessment procedures to make sure that each of them conducted the measurement procedure with confidence and consistency.

Body Mass Index measurement was based on the procedure which was proposed by [3], where the subject was asked to stand in anatomical state, his feet must be close together, the calf, backside, back and the back of the head must be against the wall. Both socks and shoes must be taken off. The assessor put or placed the equipment to measure height on top of the head. For the subject, he has to stoop and bend his knees when he was done. Having done that, the assessor had to jot down the subject's height. As for subjects' weight measurement, he was asked to stand in the middle of the weighing scale, in suitable clothes. Subject's head must be straightened with both hands remained close to the hips. Each assessor took measurements, three times and a minimum of three would be used in the measurement 
statistics. The equipment used to measure weight and height was SECA body meter Model (SECA, Germany).

Measurement procedure which utilizes Bio Impedance Analysis is based on the procedures suggested by its manufacturer which produces a type of Bio Impedance Analysis known as Tanita SC 240. Subjects were required to put on thin clothes and remove their jewelry such as rings, chains, watches and to empty their pockets. Prior to that, the assessor cleaned the platform of testing equipment. Subjects must ensure that their feet were clean and they would be asked to stand without shoes on the electron panel platform. The subjects are asked to stand upright with the feet on the metal plate with both hands on the side but slightly away from the body. The assessor took the reading three times and the value of mean would be taken to produce the scores.

In this study, the researcher used triceps locations and calf to carry out the procedure of measurement for Skinfold Test. Data from the two locations of triceps and calf. In this study, the researchers used triceps and calf locations to carry out skinfold test procedures. Results from two locations of triceps and calf were proposed as procedures in FITNESSGRAM [17]; [18]. Moreover, these two locations were accessible for the assessors while taking into consideration issues such as ethics and sensitivity of the local culture since it involved students aged 13 to 14 years old. In this research, all assessors used a caliper known as Slim Guide. According to [13], Caliper of this type has scales in millimeter unit and the pressure on subjects' $\sin$ is $7.5 \mathrm{~g} / \mathrm{mm} 2$.

Skinfold Test measurement procedure was based on a study by [13]. In order to measure triceps, the subject must stand straight in the anatomy position and hands must be straight and extended below. The assessor determined the placement for acromion and olecranon processes as well as marked the middle point between the two locations. It was marked as parallel with the arms' axis. Next, the assessor pinched the marked area one centimeter from the location of shoulders' distal and clip the caliper on the mark. Subject was not allowed to make any movement when readings were noted. In order to get the readings for the calf, the subject was asked to sit with both their feet were in vertical position to the floor. The assessor selected the widest girth and marked the pinch area which was on the medial calf on the right. He then, pinched the Skinfold on horizontal position that was proximate with the pattela. 
After that, the Caliper was put on the marked area and subjects were not allowed to make any muscle contraction while the readings were taken. Each assessor took two readings and if the second one was more than $0.2 \mathrm{~mm}$ from the previous reading, the third reading was needed. The value of min for the measurement would be recorded [1].

Having completed all three measurements, each assessor would use the formula for each result of measurement to convert data into body fat percentage estimates. Body Mass Index readings which were based on weight formula $(\mathrm{kg})$ were divided with height and the figure was divided gain with height $(\mathrm{cm})$ : this would be transformed into body fat percentage estimate by using a formula provided by [9]. $\mathrm{BF} \%=1.51 \mathrm{x}$ BMI $-0.70 \mathrm{x}$ age $-3.6 \mathrm{x}$ gender + $1.4($ male $=1$, female $=0)$. For Skinfold test reading formula, estimate of body fat used was $\%$ Fat $($ males aged 6-18 years old $)=0.735($ Triceps + Calf $)+1.0$ and \% Fat $($ females aged $6-18$ years $)=0.610($ Triceps + Calf $)+5.0$ [17]. As for the body fat estimate for Bio Impedance Analysis instrument was produced by that equipment.

The tests were conducted twice to fulfill the pre and post test method in determining the instrument's reliability. Duration of intervals between the tests was 4 hours. Pre and post test method requires similar administration of tests on the same students in two different occasions [8]. The test was administered on the students to obtain the first data set and this was repeated to get the second set. Both data were correlated to get the reliability coefficient values.

Duration of intervals to conduct the second test was considered as crucial or critical. However, the shorter the interval between the two tests, the higher the reliability of the instrument [5]. [27], in the study of body fat percentage instrument reliability allocated the interval of 24 hours to observe the level of reliability among the assessors. Reliability values among the assessors were used to obtain convergent validity among three body composition measurement instruments through field method.

\subsection{Data Analysis}

Instrument reliability is determined by using the pre and post method, by applying the Correlation Pearson Product Moment statistics to determine the reliability coefficient correlation between test one and two. [23], proposed the value of reliability coefficient 
correlation value between \pm .80 to 1.00 as high, \pm .60 to .79 slightly high, \pm .40 to .59 moderate, \pm .20 to .39 low and \pm .00 to .19 very low. Moreover, inter class reliability and intra class reliability are also taken to determine the objectivity among assessors. In order to determine the body composition measurement instruments (field method) convergent validity, the researcher used standard error measurement (SEM) formula. SEM for each body composition measurement was based on reliability coefficient pre and post test method as well as standard deviation for body composition. The formula is $\mathrm{SEM}=\mathrm{SD} \times \sqrt{ }(1-$ reliability $)$. [26], stated that the smaller the value of SEM, the higher the reliability and the test would be considered as accurate.

\section{RESULTS}

Descriptive statistics for the results are shown in Table 1.0, below. Results indicated that the mean percentage for body fat percentage based on the Body Mass Index was $(\mathrm{M}=21.3 \mathrm{SD}=$ 7.17), Bio Impedance Analysis $(M=18.65 \mathrm{SD}=9.97)$, and Skinfold Technique $(\mathrm{M}=21.8$ $\mathrm{SD}=5.97)$.

Table 1. Descriptive Statistics, Mean, Standard Deviation

\begin{tabular}{llllll}
\hline Measuring Instrument & $\mathrm{N}$ & Minimum & Maximum & Mean & Standard Deviation \\
\hline Body Mass Index & 40 & 9.83 & 41.74 & 21.3695 & 7.17872 \\
$\begin{array}{l}\text { BioImpedance } \\
\begin{array}{l}\text { Analysis } \\
\text { Skinfold Test }\end{array}\end{array}$ & 40 & 5.00 & 36.00 & 18.6550 & 9.97111 \\
& 40 & 10.70 & 36.59 & 21.8860 & 5.97681
\end{tabular}

$\mathrm{N}=40$

Table 1.1 and 1.2 show descriptive statistics from the aspects of mean and standard deviation according to gender. Results indicated that the value of mean for male subject for Body Mass Index measurement $(\mathrm{M}=23.0, \mathrm{SD}=5.69)$, Bio Impedance Analysis $(\mathrm{M}=12.31, \mathrm{SD}=9.38)$ and Skinfold Test $(\mathrm{M}=19.46 \mathrm{SD}=5.98)$. As for the female subjects, the measurement for Body Mass Index $(\mathrm{M}=19.6 \mathrm{SD}=8.20)$, Bio Impedance Analysis $(\mathrm{M}=24.9, \mathrm{SD}=5.60)$ and Skinfold Test $(\mathrm{M} 24.3 \mathrm{SD}=5.02)$. 
Table 1.1. Descriptive Statistics, Mean, Standard Deviation for Male Subjects

\begin{tabular}{llllll}
\hline $\begin{array}{l}\text { Measurement } \\
\text { Instrument }\end{array}$ & $\mathrm{N}$ & Minimum & Maximum & Mean & Standard Deviation \\
\hline Body Mass Index & 20 & 17.17 & 34.54 & 23.0600 & 5.69506 \\
Bio Impedance & 20 & 5.00 & 33.70 & 12.3150 & 9.38466 \\
Analysis & & & & & \\
Skinfold Test & 20 & 10.70 & 29.07 & 19.4680 & 5.98229 \\
\hline
\end{tabular}

$\mathbf{N}=\mathbf{2 0}$

Table 1.2. Descriptive Statistics, Mean, Standard Deviation for Female Subjects

Measurement

\begin{tabular}{llllll} 
Instrument & $\mathrm{N}$ & Minimum & Maximum & Mean & Standard Deviation \\
\hline Body Mass Index & 20 & 9.83 & 41.74 & 19.6790 & 8.20550 \\
Bio Impedance & 20 & 16.30 & 36.00 & 24.9950 & 5.60221 \\
$\begin{array}{l}\text { Analysis } \\
\text { Skinfold Test }\end{array}$ & 20 & 18.29 & 36.59 & 24.3040 & 5.02275 \\
\hline
\end{tabular}

$\mathrm{N}=20$

The main objective of this study is to determine the field method, body composition measurement instruments' reliability and convergent validity. Based on the findings, table 1.2, 1.3 and 1.4 show the reliability coefficient values for body composition, field method measurement instrument through pre and post test method. Results indicated that all instruments used namely Body Mass Index, Bio Impedance Analysis, and Skinfold Test show high reliability with the coefficient correlation value at $r=.99$ for the pre and post test method while the coefficient value of interclass and intra class reliability is between .90 to 99. Table 1.3 and 1.4 show the reliability value of body composition measurement, Bio Impedance Analysis for both male and female samples. Findings indicate that Bio Impedance Analysis has high reliability value that is $r=.99$ for both male and females. 
Table 1.3. Body Composition, Field Methodology, Measurement Instrument Reliability Coefficient Values (Bio Impedance Analysis) for male samples.

\begin{tabular}{llll}
\hline & & UJI1 BIA & UJI2 BIA \\
\hline UJI1 BIA & Pearson Correlation & 1 & $.998^{* *}$ \\
& Sig. (2-tailed) & & .000 \\
& $\mathrm{~N}$ & 20 & 20 \\
\hline
\end{tabular}

**. Correlation is significant at the 0.01 level (2-tailed).

Table 1.4. Body Composition, Field Methodology, Measurement Instrument Reliability Coefficient Values (Bio Impedance Analysis) for female samples.

\begin{tabular}{llll}
\hline & & UJI1 BIA & UJI2 BIA \\
\hline UJI1 BIA & Pearson Correlation & 1 & $.983^{* *}$ \\
& Sig. (2-tailed) & & .000 \\
& $\mathrm{~N}$ & 20 & 20 \\
\hline
\end{tabular}

**. Correlation is significant at the 0.01 level (2-tailed).

Table 1.5 and 1.6 indicate the reliability coefficient value of body composition measurement using Body Mass Index as an instrument, for both male and female samples. Findings show the coefficient value for body composition Body Mass Index for male and female samples. It is reported that the Body Mass Index as an instrument has high reliability value $r=.99$ for both male and female samples.

Table 1.5. Body Composition, Field Methodology, Measurement Instrument Reliability Coefficient Values (Body Mass Index) for male samples

\begin{tabular}{llll}
\hline & & UJI1 BMI & UJI2 BMI \\
\hline UJI1 BMI & Pearson Correlation & 1 & $.998^{* *}$ \\
& Sig. (2-tailed) & & .000 \\
N & 20 & 20 \\
\hline
\end{tabular}

**. Correlation is significant at the 0.01 level (2-tailed). 
Table 1.6. Body Composition, Field Methodology, Measurement Instrument Reliability Coefficient Values (Body Mass Index) for female samples

\begin{tabular}{llll}
\hline & & UJI1 BMI & UJI2 BMI \\
\hline UJI1 BMI & Pearson Correlation & 1 & $.999^{* *}$ \\
& Sig. (2-tailed) & & .000 \\
& $\mathrm{~N}$ & 20 & 20 \\
\hline
\end{tabular}

**. Correlation is significant at the 0.01 level (2-tailed).

Table1.7 and 1.8 show the reliability coefficient value of body composition instrument for Skinfold Test among male and female samples. Findings show that Skinfold Test as an instrument has high reliability value that is $r=.99$ for both male and female students. Based on the results obtained, reliability coefficient value via pre and post test method for the measurement instrument for body composition, field methodology has a high value of coefficient correlation at $r=.99$.

Table 1.7 Reliability Coefficient Value of Body Composition Measurement Instrument through Skinfold Test for Male Samples.

\begin{tabular}{llll}
\hline & & UJI1 SKF & UJI2 SKF \\
\hline UJI1 SKF & Pearson Correlation & 1 & $.996^{* *}$ \\
& Sig. (2-tailed) & & .000 \\
& $\mathrm{~N}$ & 20 & 20 \\
\hline
\end{tabular}

**. Correlation is significant at the 0.01 level (2-tailed).

Table 1.8. Reliability Coefficient Value of Body Composition Measurement Instrument through Skinfold Test for Female Samples

\begin{tabular}{llll}
\hline & & UJI1 SKF & UJI2 SKF \\
\hline UJI1 SKF & Pearson Correlation & 1 & $.992^{* *}$ \\
& Sig. (2-tailed) & & .000 \\
& $\mathrm{~N}$ & 20 & 20 \\
\hline
\end{tabular}

**. Correlation is significant at the 0.01 level (2-tailed).

Body composition field method test's objectivity in this study was obtained through interclass reliability and intra class reliability [24], where the value of objectivity coefficient is obtained through correlation pearson'r [2]. Correlation coefficient value of inter class and 
intra class in this research is between .90 to .99 that has fulfilled the correlation as suggested by [3].

Table 1.9 indicates the correlation coefficient values between scores of assessor 1 and 2 is $r=$ .93 , scores among assessor 1 and the expert are at $r=.93$ and between assessor 2 and the expert is at $r=.99$. These show that both assessors have high value of objectivity together with the expert in the measurement for Body Mass Index.

Table 1.9. Intra Class and Inter Class Reliability of Body Mass Index for Male Subjects

\begin{tabular}{llll}
\hline & & Assessor 2 & Expert \\
\hline Assessor & Pearson Correlation & $932^{* *}$ & $.931^{* *}$ \\
& Sig. (2-tailed) & .000 & .000 \\
& $\mathrm{~N}$ & & \\
\hline Assessor & Pearson Correlation & $.999^{* *}$ \\
2 & Sig. (2-tailed) & .000 \\
& $\mathrm{~N}$ & 20 \\
\hline **. Correlation is significant at the 0.01 level (2-tailed). \\
\hline
\end{tabular}

Table 1.10, shows the correlation coefficient values of scores between assessor 2 and 4 is at $r$ $=.99$, scores among assessor 3 with female expert was $r=.99$ and among assessor 4 and the expert was $r=.99$. These indicate that both assessors have high objectivity values together with the expert in the measurement of Body Mass Index.

Table 1.10. Intra Class Reliability Female Assessor and Body Mass Index

\begin{tabular}{llll}
\hline & & Assessor 4 & Expert \\
\hline Assessor 3 & Pearson Correlation & $995^{* *}$ & $.997^{* *}$ \\
& Sig. (2-tailed) & .000 & .000 \\
& $\mathrm{~N}$ & & \\
\hline Assessor 4 & Pearson Correlation & $.996^{* *}$ \\
& Sig. (2-tailed) & .000 \\
& $\mathrm{~N}$ & 20 \\
\hline **. Correlation is significant at the 0.01 level (2-tailed). \\
\hline
\end{tabular}


Table 1.11 shows the correlation coefficient values between scores of assessor 1 and assessor 2 at $r=.99$, the scores among assessor 1 and the expert are at $r=.99$ and between assessor 2 scores and the experts' was at $r=.99$. These indicate that both assessors have high objectivity values in the measurement of Bio Impedance Analysis.

Table 1.11: Intra Class and Inter Class Reliability Male Assessor, Bio Impedance Analysis.

\begin{tabular}{llll}
\hline & & Assessor 2 & Expert \\
\hline Assessor 1 & Pearson Correlation & $998^{* *}$ & $.997^{* *}$ \\
& Sig. (2-tailed) & .000 & .000 \\
& $\mathrm{~N}$ & & \\
\hline Assessor & Pearson Correlation & $.997^{* *}$ \\
2 & Sig. (2-tailed) & .000 \\
& $\mathrm{~N}$ & 20 \\
\hline **. Correlation is significant at the 0.01 level (2-tailed). \\
\hline
\end{tabular}

Table 1.12 indicates the value of coefficient correlation between scores from assessor 3 and assessor 4 is at $r=.95$, scores between assessor 3 and the expert is at $r=.96$ and between assessor 4 and the expert is $r=.99$. These indicate that both assessors have high objectivity value with the expert in the measurement of Bio Impedance Analysis.

Table 1.12. Intra Class dan Inter Class Reliability Female Assessor Bio Impedance Analysis.

\begin{tabular}{llll}
\hline & & Assessor 4 & Expert \\
\hline Assessor 3 & Pearson Correlation & $951^{* *}$ & $.968^{* *}$ \\
& Sig. (2-tailed) & .000 & .000 \\
& $\mathrm{~N}$ & & \\
\hline Assessor 4 & Pearson Correlation & $.991^{* *}$ \\
& Sig. (2-tailed) & .000 \\
& $\mathrm{~N}$ & 20 \\
\hline **. Correlation is significant at the 0.01 level (2-tailed). \\
\hline
\end{tabular}

Table. 13 indicates the correlation coefficient values of scores from assessor 1 and 2 is at $r=$ .97 , scores between assessor 1 and the expert is $r=.98$ and between assessor 2 and the expert 
is at $r=.98$. These indicate that both assessors have high objectivity value in the Skinfold Test.

Table 1.13. Intra Class dan Inter Class Reliability Male Assessor Skinfold Test

\begin{tabular}{llll}
\hline & & Assessor 2 & Expert \\
\hline Assessor 1 & Pearson Correlation & $975^{* *}$ & $.980^{* *}$ \\
& Sig. (2-tailed) & .000 & .000 \\
& $\mathrm{~N}$ & & \\
\hline Assessor 2 & Pearson Correlation & $.988^{* *}$ \\
& Sig. (2-tailed) & .000 \\
& $\mathrm{~N}$ & 20 \\
\hline
\end{tabular}

**. Correlation is significant at the 0.01 level (2-tailed).

Table 1.14 indicates the correlation coefficient between scores of assessor 3 and 4 is at $r=$ .95 , scores between assessor 3 and the expert is at $r=.98$ and between assessor 4 and the expert is at $r=.96$. These indicate that both assessors have high objectivity value for Skinfold Test.

Table 1.14. Intra Class and Inter Class Reliability Female Assessors Skinfold Test

\begin{tabular}{llll}
\hline & & Assessor 4 & Expert \\
\hline Assessor 3 & Pearson Correlation & $959^{* *}$ & $.981^{* *}$ \\
& Sig. (2-tailed) & .000 & .000 \\
& $\mathrm{~N}$ & \\
\hline Assessor 4 & Pearson Correlation & $.965^{* *}$ \\
& Sig. (2-tailed) & .000 \\
& $\mathrm{~N}$ & 20 \\
\hline **. Correlation is significant at the 0.01 level (2-tailed). \\
\hline
\end{tabular}

Correlation coefficient value of interclass reliability and intraclass reliability which is obtained brings forth all the measurement instruments used for measuring body composition , field methodology, that are represented by Body Mass Index, Bio Impedance Analysis, and Skinfold Test which were all used in this study have high value of objectivity. Correlation coefficient value of inter class and intra class in this study are between .90 to .99 which has fulfilled the value of correlation as proposed by [3]. 
In addition, convergent validity that is determined through SEM values is shown in Table 1.15 and 1.16. Based on the findings, Body Mass Index showed the smallest value of standard error measurement for both male and female samples. Average standard error measurement for male samples for Body Mass Index was 0.000611642 compared to Bio Impedance Analysis (0.000741555) instrument and Skinfold Analysis (0.002568187). The value of standard error measurement for female samples too showed Body Mass Index has the smallest value that is 0.000635793 as compared to Bio Impedance Analysis (0.046019617), and Skinfold Test (0.065473292). Thus, Body Mass Index is the instrument which has the highest level of accuracy as compared to Bio Impedance Analysis and Skinfold Test in measuring the percentage of body fat for both male and female students aged 13 to 14 years old in the vicinity of Klang, Selangor.

Table 1.15. Standard Error Measurement value among assessor and assistant assessor together with the assistant assessor for body composition measurement for male samples.

\begin{tabular}{lllllll}
\hline & $r$ & & \multicolumn{4}{l}{ Standard Error Measurement } \\
\cline { 2 - 7 } Assessori & BMI & BIA & SKF & BMI & BIA & SKF \\
Researcher & .99 & .99 & .99 & 0.000691729 & 0.000502891 & 0.00054918 \\
& & & & & & 7 \\
Assessor 1 & .99 & .99 & .97 & 0.000678821 & 0.000568401 & 0.00519039 \\
& & & & & & 9 \\
Assessor 2 & .99 & .99 & .98 & 0.000464375 & 0.001153374 & 0.00196497 \\
& & & & & & 6 \\
Average & & & & 0.000611642 & 0.000741555 & 0.00256818 \\
& & & & & & 7 \\
\hline
\end{tabular}


Table 1.16. Standard Error Measurement value among assessor and assistant for body composition instrument measurement for female samples

\begin{tabular}{lllllll}
\hline & $r$ & & \multicolumn{4}{l}{ Standard Error Measurement } \\
\cline { 2 - 7 } Assessor & BMI & BIA & SKF & BMI & BIA & SKF \\
Expert & .99 & .99 & .99 & 0.000709297 & 0.005945020 & 0.00062282 \\
Assessor 3 & .99 & .99 & .96 & 0.000733708 & 0.000605332 & 0.00923958 \\
& & & & & & 4 \\
Assessor 4 & .99 & .95 & .94 & 0.000464375 & 0.131508500 & 0.12170700 \\
& & & & & & 0 \\
Average & & & & 0.000635793 & 0.046019617 & 0.06547329 \\
& & & & & & 2 \\
\hline
\end{tabular}

\section{CONCLUSION AND DISCUSSION}

This study aims to determine the body composition measurement instruments' reliability and convergent validity in field methodology (Body Mass Index, Bio Impedance Analysis, Skinfold Test) among students aged 13 and 14 years old in Klang, Selangor. There are various body composition measurement instrument in the field methodology, which are often used to determine the body fat percentage. However, Body Mass Index, Bio Impedance Analysis, and Skinfold test are among the popular ones and often used since the measurement method is simple. Skinfold Test is also among those which are popular and often used due to the fact that it is not costly, uses simple method, easy to be applied on a bigger group and minimum amount of equipment.

Research results show that all three instruments (Body Mass Index, Bio Impedance Analysis, Skinfold Theory) have their own high reliability based on the pre and post test method as well as the assessors' objectivity. Reliability coefficient indicates that the values of all three instruments are at $r=.99$. On the other hand, inter class reliability objectivity is at $r=.99$ for Body Mass Index and Bio Impedance Analysis. As for Skinfold Test, results show the value of $\mathrm{r}=.96$. For intra class reliability, it shows a high level of objectivity values at .90 to .99 for all three instruments. High reliability recorded for all three instruments is the result of all assessors who used standard procedures and administration of tests. Nevertheless, Skinfold 
Test shows a low level of objectivity as compared to Body Mass Index and Bio Impedance Analysis since all assistant assessors are novices in research.

Findings in this research support the results presented by [24], who found that inter observer reliability for Body Mass Index was very high which surpasses $r=.99$ and it is concluded that Body Mass Index remain as the instrument to identify obesity as compared to waist circumference and ratio of hip circumference. Results of this study are also in line with the findings by [4], who found that inter rater and intra rater reliability for Body Mass Index was high as it went beyond 0.96. They also realized that there were several issues which jeopardized reliability such as challenges in equipment such as inaccurate, data recording, measurement scale, and problems like interference in the form of students' hair or clothes. In addition, [7], also found that intra class correlation coefficient for Body Mass Index used to measure women, babies and children yielded high records such as $0.96,0.99$. and 0.93 .

Based on the findings from previous researches, it is clear that inter rater and intra rater reliability for Body Mass Index in this study is parallel. This is indicative of Body Mass Index as the reliable and suitable instrument to be used to measure body composition and it can be utilized to detect obesity. Referring to past studies by previous researchers [25] and [28], Body Mass Index is the one of the most accurate fat evaluation to identify obesity as well as a close relation to identification of cardiovascular diseases.

Even though Skinfold Test showed low inter class and intra class objectivity compared to Body Mass Index and Bio Impedance Analysis but the value of $r=.96$ and .90 is below the "very good" level in terms of the value of objectivity. However, Pearson correlation coefficient value is high at $r=.99$. These findings are also in line with results produced by [11], who showed tht Body Mass Index $(r=.50)$ has reliability coefficient that is higher than Skinfold test $(r=.47)$. It is too low to identify the factors of cardiovascular diseases among children and teenagers. A lower value than the Body Mass Index is indicative of the assessor's incompetency in the procedures and administration of Skinfold Test. These are due to the fact that the most schools in Malaysia rarely used Skinfold Test to measure the percentage of body fat compared to the the use of Body Mass Index. 


\section{RECOMMENDATION}

Pre and Post test method reliability for Body Mass Index, Bio Impedance Analysis, and Skinfold Test is high because the measurement administration, measurement time, surrounding areas in which the test was carried out was consistent between pre and post test results. Body Mass Index is the most accurate instrument in measuring body composition for subjects aged 13 to 14 years old in Klang, Selangor, based on convergent validity method.

\section{REFERENCES}

[1] Aandstad, A., Holtberget, K., Hageberg, R., Holme, I., \& Anderssen, S. a. (2014). Validity and reliability of bioelectrical impedance analysis and skinfold thickness in predicting body fat in military personnel. Military Medicine, 179(2), 208-17.

[2] Ahmad Hashim. (2015). Pengujian Pengukuran dan Penilaian Pendidikan Jasmani.

Selangor: Dubook Press Sdn Bhd.

[3] Baumgartner, T. A, Jackson, A. S., Mahar, M. T., \& Rowe, D. A. (2006). Measurement for evaluation in physical education \& exercise science ( $8^{\text {th }}$ ed.). New York: McGraw Hill [4] Berkson, S. S., Espinola, J., Corso, K. A., Cabral, H., McGowan, R., \& Chomitz, V. R. (2013). Reliability of Height and Weight Measurements Collected by Physical Education Teachers for a School-Based Body Mass Index Surveillance and Screening System. Journal of School Health, 83(1), 21-27.

[5] Bishop, P.A. (2008). Measurement and Evaluation in Physical Activity Applications. Arizona. Holcomb Hathaway.

[6] Chu, N. F. (2001). Prevalence and trends of obesity among school children in Taiwan-theTaipei Children Heart Study. International Journal of Obesity \& Related Metabolic Disorders, 25(2). 170-177

[7] Crespi, C. M., Alfonso, V. H., Whaley, S. E., \& Wang, M. C. (2012). Validity of child anthropometric measurements in the Special Supplemental Nutrition Program for Women, Infants, and Children. Pediatric research, 71(3), 286-292.

[8] DeVon, H. A., Block, M. E., Moyle-Wright, P., Ernst, D. M., Hayden, S. J., Lazzara, D. J., Savoy, S. M., \& Kostas-Polston, E. (2007). A psychometric toolbox for testing validity and reliability. Journal of Nursing scholarship, 39(2), 155-164. 
[9] Deurenberg, P., Weststrate, J. A., \& Seidell, J. C. (1991). Body mass index as a measure of body fatness: age-and sex-specific prediction formulas. British journal of nutrition, 6(5), $105-114$.

[10] Dietz, W. H. (1998). Health consequences of obesity in youth: childhood predictors of adult disease. Pediatrics, 101(Supplement 2), 518-525.

[11] Freedman, D. S., Katzmarzyk, P. T., Dietz, W. H., Srinivasan, S. R., \& Berenson, G. S. (2009). Relation of body mass index and skinfold thicknesses to cardiovascular disease risk factors in children: the Bogalusa Heart Study. The American journal of clinical nutrition, 90(1), 210-216.

[12] Guo, B., Aveyard, P., Fielding, A., \& Sutton, S. (2008). Testing the convergent and discriminant validity of the Decisional Balance Scale of the Transtheoretical Model using the Multi-Trait Multi-Method approach. Psychology of Addictive Behaviors, 22(2), 288.

[13] Heyward, V.H. and Wagner, D.R.(2004). Applied Body Composition Assesment. (2nd ed.).Champaign,IL: Human Kinetics.

[14] Lindberg, S. M., Adams, A. K., \& Prince, R. J. (2012). Early predictors of obesity and cardiovascular risk among American Indian children. Maternal and child health journal, 16(9), 1879-1886.

[15] Linn, R., Gronlund, N. (2000). Measurement and assessment in teaching. New Jersey: Prentice Hall

[16] Lobstein T., \& Frelut, M. L. (2003). Prevalence of overweight among children in Europe. Obesity reviews, 4(4), 195-200.

[17] Lohman, T. G., \& Going, S. B. (1998). Assessment of body composition and energy balance. Perspectives in exercise science and sports medicine, 11, 61-98.

[18] Mooney, A., Kelsey, L., Fellingham, G. W., George, J. D., Hager, R. L., Myrer, J. W., \& Vehrs, P. R. (2011). Assessing body composition of children and adolescents using dual-energy X-ray absorptiometry, Skinfold, and electrical impedance. Measurement in Physical Education and Exercise Science, 15(1), 2-17.

[19] Morrow, J.R., Jackson, A.W., Disch, J.G., \& Mood, D.P. (2011). Measurement and evaluation in human performance (4 ${ }^{\text {th }}$ ed.). Champaign, IL: Human Kinetics. [20] Morrow, J.R., Jackson, A.W., Disch, J.G., \& Mood, D.P. (2000). Measurement and 
evaluation in human performance ( $2^{\text {th }}$ ed.). Champaign, IL: Human Kinetics.

[21] Must, A. (1996). Morbidity and mortality associated with elevated body weight in children and adolescents. The American journal of clinical nutrition, 63(3), 445S-447S.

[22] Norimah, A.K., Ruzita, A.T., Poh, B.K.,Nurunnajiha, N., Wong, J.E., Raduan, S., \&Ismail,M.N., (2009). Food habits and physical activity pattern among primary school children in Malaysia. Conference Paper. Nutrition Society of Malaysia. 24th Scientific Conference, p 38

[23] Safrit, M. J. (1995). Complete Guide to Youth Fitness Testing. New York : Human Kinetics.

[24] Sebo, P., Beer-Borst, S., Haller, D. M., \& Bovier, P. A. (2008). Reliability of doctors' anthropometric measurements to detect obesity. Preventive medicine, 47(4), 389-393.

[25] Sun, Q., Van Dam, R. M., Spiegelman, D., Heymsfield, S. B., Willett, W. C., \& Hu, F. B.(2010). Comparison of dual-energy x-ray absorptiometric and anthropometric measures of adiposity in relation to adiposity-related biologic factors. American journal of epidemiology, 172(12):1442-54.

[26] Tighe, J., McManus, I. C., Dewhurst, N. G., Chis, L., \& Mucklow, J. (2010). The standarderror of measurement is a more appropriate measure of quality for postgraduate medical assessments than is reliability: an analysis of MRCP (UK) examinations. BMC medical education, 10(1), 1-9

[27] Vicente-Rodríguez, G., Rey-López, J. P., Mesana, M. I., Poortvliet, E., Ortega, F. B., Polito, A., Nagy, E., Widhalm, K., Sjostrom, M., \& Moreno, L. A. (2012). Reliability and intermethod agreement for body fat assessment among two field and two laboratory methods in adolescents. Obesity, 20(1), 221-228.

[28] Weber, D. R., Leonard, M. B., Shults, J., \& Zemel, B. S. (2014). A comparison of fat and lean body mass index to BMI for the identification of metabolic syndrome in children and adolescents. The Journal of Clinical Endocrinology \& Metabolism, 99(9), 3208-3216.

[29] WHO. (2004). Expert consultation. Appropriate body-mass index for Asian populations and its implications for policy and intervention strategies. Geneva: World Health Organization.

\section{How to cite this article:}

Hashim A., Elumalai G., and Ab Rahman Z. Reliability and validity for measurement of body composition: a field method. J. Fundam. Appl. Sci., 2017, 9(6S), 1187-1206. 